\title{
Correspondence
}

\section{Difficult intubation}

To the Editor:

May we comment on the excellent article "Difficult intubation in the parturient" by Drs. Davies et al.

Two years ago we introduced the Brain laryngeal airway into routine use in our hospital. We also keep sizes 3 and 4 in our failed intubation pack. In the past year we had two elective lower segment Caesarean sections under general anaesthesia where a laryngeal airway was used successfully after failed intubation. The first was a parturient with a Class 3 risk as defined by Mallampati. ${ }^{2}$ The second was found at laryngoscopy to have a Grade 2 assessment as per Cormack. ${ }^{3}$ On both occasions intubation by experienced anaesthetists failed, but in both a size 3 Brain laryngeal airway was inserted directly and easily in the left lateral position with cricoid pressure being maintained. Gentle manual ventilation with halothane in oxygen was performed until spontaneous respiration was established; then anaesthesia was maintained with 50 per cent oxygen in nitrous oxide and halothane. Uterine atony did not manifest itself clinically. The quick and smooth recovery together with the lack of recall of peroperative events was reassuring.

Like Reynolds ${ }^{4}$ we too believe that the larygeal airway "represents the ideal fall back position" and its use in the failed intubation drill $1^{5}$ needs to be considered - a view suggested by Tunstall. ${ }^{6}$

W.F. de Mello BSc FCAnaes, DRCOG

J. Restall, FFARCS

Cambridge Military Hospital

Aldershot, Hants, GUII 2AN

\section{REFERENCES}

1 Davies JM, Creeks S, Crone LA, Pavlin E. Difficult intubation in the parturient. Can J Anaesth 1989; 36: 668-74.

2 Mallampati SR, Gall SP, Gugino LD et al. A clinical sign to predict difficult tracheal intubation: a prospective study. Can Anaesth Soc J 1985; 32: 429-34.

3 Cormack RS, Lehane J. Difficult tracheal intubation in obstetrics. Anaesthesia 1985; 39: 1105-11.

4 Reynolds $F$. Tracheostomy in obstetric practice - how about the laryngeal airway? Anaesthesia 1989; 44: 870 .

5 Tunstall ME. Failed intubation drill. Anaesthesia 1976; 31: 850 .

6 Tunstall $M E$. Failed intubation in the parturient. Can J Anaesth $1989 ; 36: 611-3$

\section{Failed intubation: a different perspective}

\section{To the Editor:}

All the methods of cricothyrotomy reviewed by Davies $e t$ al. ${ }^{1}$ have shortcomings. Furthermore cricoid pressure is no longer a practical method of protecting the airway once the cricothyrotomy catheter is in place. I would appreciate an opportunity to state my preference and suggest some solutions.

During jet ventilation, the shaft of the cannula must be in line with the long axis of the trachea. Needle cricothyrotomy in patients with short bull necks can be successful only if the needle is advanced in a direction perpendicular to the trachea. Any attempt to re-direct the plastic cannula caudad will cause it to kink and obstruct the jet flow. Jetting at right-angles to the tracheal axis can only serve to introduce pure oxygen into the airway and maintain oxygenation; it does not provide adequate ventilation. Jetting against the posterior tracheal wall can also tear its muscosal lining. The incidence of surgical emphysema, respiratory difficulty, perforation of blood vessels is as high as 29 per cent when this technique is used in an emergency. ${ }^{2}$ Examination of CMPA records show that there has been at least one successful claim by a victim from injuries caused by transtracheal jet ventilation. This technique can save lives in dire emergencies, but it can also maim and kill. It is not a technique for the uninitiated, particularly in a near panic situation.

Emergency surgical cricothyrotomy can be difficult because of obscured landmarks in patients with bull necks. But there are methods assisted by devices that begin with needle cricothyrotomy. Once the tracheal lumen is entered, a guide and a dilator are introduced to be followed by the airway. Unfortunately not all cricothyrotomy tubes are equipped with cuffs, and some built-in cuffs are easily damaged during insertion. In the absence of an intact cuff, adequate IPPV is difficult, even when the oxygen flush valve is activated to compensate for gas leak through the glottis. In this situation a useful manoeuvre is to depress the mandible posteriorly so as to force the tongue to lie flat against the posterior pharyngeal wall and into the larynx. Obstruction of the glottis by this method will reduce back flow leak and allow ventilation of the lungs using normal fresh gas flows.

However, the method described also has pitfalls. First of all, the airway remains unprotected; secondly, some of the gas leak can be forced down the oesophagus. 
Therefore an oesophageal obturator with an inflatable cuff should be used to isolate the oesophagus from the trachea. An effective obturator can be fashioned quickly from a tracheal tube by blocking its connector end using a rubber bung from blood sample tubes, bone wax, or waterproof tapes etc. After introduction, the pilot balloon and its conduit should be left outside the mouth and taped to the patient's cheek. This home-made device has one advantage over manufactured obturators that have blind distal ends: the connector end can be unblocked outside the mouth at the conclusion of the procedure and the stomach emptied by a Levine-type tube first before its removal. This is not possible with commercial obturators, and gastric contents built up behind the blind end can well into the pharynx following removal, leading to aspiration.

IPPV using mask and cricoid pressure combination is regarded by many as an acceptable method to proceed with anaesthesia and surgery in a fail-to-intubate-butable-to-ventilate situation. In my opinion it is not a practical alternative because (a) cricoid pressure tends to flex the head and neck and force the tongue to lie flat against the posterior pharyngeal wall, causing airway obstruction, and (b) steady cricoid pressure cannot be maintained for any length of time due to muscle fatigue. The best alternative is to use the oesophageal obturator described earlier as an adjunct to IPPV via a face mask.

\section{David C. Chung MD FFARCS FRCPC}

Department of Anaesthesia,

The Mississauga Hospital,

Mississauga, Ontario.

\section{REFERENCES}

1 Davies JM, Weeks S, Crone LA, Pavlin E. Difficult intubation in the parturient. Can J Anaesth 1989; 36: 668-74.

2 Smith RB, Babinski $M$, Klain $M$, Pfaeffle $H$. Percutaneous transtracheal ventilation. J Am Coll Emerg Physicians 1976; 5: 765-70.

\section{Respiratory arrest following interpleural block in a narcotized patient}

\section{To the Editor:}

There is considerable interest in the technique of interpleural (intrapleural) infusion of local anaesthetics to provide analgesia following surgery. However, an incident occurred in our recovery room which may have been due to the technique.

A 72-yr-old male, ASA physical status II, was scheduled for right adreno-nephrectomy. Ninety minutes before surgery he received temazepam $30 \mathrm{mg}$ and metoclopramide $10 \mathrm{mg}$ by mouth. Anaesthesia was induced with thiopentone. Muscle relaxation was achieved with vecuronium, and anaesthesia was maintained with enflurane, $\mathrm{N}_{2} \mathrm{O}$, and morphine. The total dose of morphine administered IV was $45 \mathrm{mg}$, with the last dose of $6 \mathrm{mg}$ being given $45 \mathrm{~min}$ before the end of surgery. Enflurane was discontinued $60 \mathrm{~min}$ before the surgery was completed.

Operating time was four hours. After surgical closure, the anaesthetist introduced a 16-gauge Portex epidural catheter into the pleural space. Neostigmine $2.5 \mathrm{mg}$ and atropine $1.2 \mathrm{mg}$ were given IV which produced full return of neuromuscular function. When the patient then awoke he gestured that he was "OK" and shook his head when questioned about pain. The trachea was then extubated. Bupivicaine 0.5 per cent $20 \mathrm{ml}$ was injected through the interpleural catheter and the patient was transferred to the neighboring recovery room where oxygen $6 \mathrm{~L} \cdot \mathrm{min}^{-1}$ were administered via face mask. The patient appeared drowsy but again made a hand gesture to indicate that he felt "OK." Heart rate and blood pressure were within normal limits. Approximately two minutes later, the recovery room nurse reported that the patient was apnoeic and cyanotic. Naloxone was prepared but withheld as the patient continued to breathe adequately. Eighty minutes after the respiratory arrest, an interpleural infusion of bupivicaine 0.5 per cent was started at $7 \mathrm{ml} \cdot \mathrm{hr}^{-1}$ and the patient was discharged from the recovery room. The infusion was continued for three days at rates of $5-7 \mathrm{ml} \cdot \mathrm{hr}^{-1}$ and subsequent recovery was uneventful.

We have found that the onset of analgesia is rapid when a $20 \mathrm{ml}$ bolus of bupivicaine 0.5 per cent is administered interpleurally following abdominal surgery. On occasion, pain has been alleviated within ten minutes. This appears more rapid than in Strömskag's experience, who reported that 30 minutes is usually required before most patients experience complete pain relief. ${ }^{1}$ Following selected abdominal operations, an interpleural catheter is introduced before the patient is awake but the first dose of local anaesthetic is withheld until the patient is breathing spontaneously and is responsive; and after tracheal extubation. In the case described here, the patient was responding to verbal command and breathing well. However, in the absence of surgical pain, it was probably unwise to administer local anaesthetic in a patient with residual "narcotization." The interval between administration of interpleural local anaesthetic and the respiratory arrest was between five and ten minutes. We suspect that there was a rapid and complete onset of analgesia which upset the balance between the residual effect of the narcotic and the surgical stimulus from the wound. With further experience in this technique of postoperative 